\title{
Investigation of ductile iron casting process parameters using Taguchi approach and response surface methodology
}

\author{
${ }^{*}$ A. Johnson Santhosh' and A. R. Lakshmanan' \\ 1. Dept of Mechanical Engineering, PPG Institute of Technology, Coimbatore, India \\ 2. Dept of Mechanical Engineering, PSG College of Technology, Coimbatore, India
}

\begin{abstract}
To find the optimized levels of various casting parameters in the ductile iron casting, various casting defects and the rejection rate were observed from a medium scale foundry. The controlled values of different casting parameters such as pouring temperature, inoculation, carbon equivalent, moisture content, green compression strength, permeability and mould hardness were selected. Three different melts of metal with $0.4 \mathrm{wt} . \%$, $0.6 \mathrm{wt} . \%$, and $0.8 \mathrm{wt} . \%$ inoculation (Fe-Si-Mg alloy and post inoculant) were produced using a 1-ton capacity coreless medium frequency induction furnace. L-27 orthogonal array with 3-level settings were chosen for the analysis. Responses for each run were observed. The signal-to-noise $(\mathrm{S} / \mathrm{N})$ ratio for each run was calculated using the Taguchi approach, and the optimized levels of different casting parameters were identified based on the S/N ratio. The analysis of variance for the casting acceptance percentage concludes that inoculation is the most significant factor affecting the castings' quality with a contribution percentage of $44 \%$; an increase in inoculation results in a significant improvement in acceptance percentage of ductile iron castings. The experiment results showed that with the optimized parameters, the rejection rate was reduced from $16.98 \%$ to $6.07 \%$.
\end{abstract}

Key words: optimized levels; casting parameters; S/N ratio; Taguchi approach; ANOVA; 'F'-Test
CLC numbers: TG143.5
Document code: A
Article ID: 1672-6421(2016)05-352-09

\begin{abstract}
$A_{p}$ defective casting leads to a tremendous loss of productivity ${ }^{[1]}$. Ductile cast iron has excellent mechanical properties, such as high strength, good ductility, good wear resistance and good fatigue properties. The properties of ductile cast iron are dependent on both chemistry and heat treatment ${ }^{[2]}$. Many steel components are replaced by ductile iron due to high strength to weight ratio and range of properties. Ductile iron provides a good combination of strength and ductility due to the presence of spheroid graphite ${ }^{[3]}$. Modification of various alloys is a well known process for improving the properties by changes of microstructure ${ }^{[4]}$. Even small changes in element content lead to statistically significant increases or decreases in mechanical properties of cast iron. Proper selection of process parameters is necessary in order to obtain a good quality and subsequently increase the productivity of the process ${ }^{[5]}$. Carbon equivalent
\end{abstract}

\footnotetext{
* A. Johnson Santhosh
}

Male, born in 1987, Assistant Professor, ASME member. His research mainly focuses on quality control, defects, and ductile iron casting process.

E-mail: johnsonsanthosh@gmail.com

Received: 2015-12-28; Accepted: 2016-07-11 value enhances the fluidity of molten metal as well as having great effects on the mechanical properties of cast products ${ }^{[6]}$. Good quality casting can be achieved by optimization of controllable process parameters such as mould hardness, moisture content, permeability and green compression strength ${ }^{[7]}$. Analysis of variance (ANOVA) results indicate that the selected process parameters significantly affect the casting defects and rejection percentage ${ }^{[8-13]}$. An orthogonal array was used to implement Taguchi Methodology ${ }^{[14-16]}$. The Taguchi method stresses the importance of studying the response variation using the signal-to-noise $(\mathrm{S} / \mathrm{N})$ ratio, resulting in minimization of quality characteristic variations due to uncontrollable parameters ${ }^{[17,18]}$. The $\mathrm{S} / \mathrm{N}$ ratio values are calculated using the software Minitab ${ }^{[19,20]}$. The settings of the process parameters were determined by using Taguchi's experimental design method ${ }^{[21-23]}$. In order to optimize the sand casting process parameters of the castings manufactured in an iron foundry, the Taguchi method was used to maximize the $\mathrm{S} / \mathrm{N}$ ratios and minimize the noise factors. Response Surface Method predicts better optimal response with respect to significant factors ${ }^{[24-25]}$.

In this research, the various defects which easily occur 
in ductile iron castings were observed from a medium scale foundry. Most of the components produced in these experiments have a range of $500 \mathrm{~g}$ to $2 \mathrm{~kg}$ in weight and $5 \mathrm{~mm}, 10 \mathrm{~mm}$, $15 \mathrm{~mm}$ in thickness. These components were widely used for automobile applications like flanges and couplings, and the rejection report for a batch of different components is listed in Table 1.

In order to decrease the rejection rate, various casting parameters such as pouring temperature, inoculation, carbon equivalent, moisture content, green compression strength,

Table 1: History of casting defects in a foundry

\begin{tabular}{ccc|} 
Defect & No. of rejected & $\begin{array}{c}\text { Rejection } \\
\text { rate (\%) }\end{array}$ \\
\hline Crack & 55 & 3.67 \\
Cold shut & 47 & 3.13 \\
Poor mould & 38 & 2.53 \\
Mismatch & 31 & 2.07 \\
Fettling fault & 29 & 1.93 \\
Slag & 22 & 1.47 \\
Run out & 17 & 1.13 \\
Scab & 13 & 0.87 \\
Swell & 9 & 0.60 \\
Less hardness & 8 & 0.53 \\
Others & 6 & 0.40 \\
Inspected & 275 & 16.98 \\
components $=1,620$ & &
\end{tabular}

permeability and hardness were chosen for investigation. The optimum values of different process parameters were finally selected using the Taguchi method.

\section{Experimental procedure}

\subsection{Chemical analysis of materials}

The melt charge consisting of $12 \%-15 \%$ pig iron, $25 \%-30 \%$ foundry returns and remaining steel scrap were melted in a 1-ton capacity coreless medium frequency induction furnace. The chemical compositions of raw materials were tested by spectrometer analysis and are listed in Table 2. The molten metal was tapped in a preheated ladle containing Fe-Si-Mg alloy in size of $20-25 \mathrm{~mm}$ at the bottom covered with steel scrap. The tapping temperature of molten metal was $1,300{ }^{\circ} \mathrm{C}, 1,350{ }^{\circ} \mathrm{C}$ and $1,400{ }^{\circ} \mathrm{C}$, respectively. The inoculants were then added in the base melt, while pouring directly in the stream for proper mixing. Inoculants of size 4 to $8 \mathrm{~mm}$ were added in the molten metal stream so as to dissolve easily and should be dust free to avoid losses due to oxidation or thermal air currents. Inoculation was the total amount of Fe-Si-Mg alloy and post inoculant, of which Fe-Si-Mg alloy was about 90wt.\% and post inoculant 10wt.\%. Based on this proportion, various percentage of inoculation was added with the base metal of 1,000 kg. Tables 3 and 4 list the chemical compositions of Fe-Si-Mg alloy and post inoculant, and the metal with $0.4 \mathrm{wt} . \%, 0.6 \mathrm{wt} . \%$ and $0.8 \mathrm{wt} . \%$ inoculation.

Table 2: Chemical compositions of furnace charge by spectroscopic analysis (wt.\%)

\begin{tabular}{ccccccccc}
$\begin{array}{c}\text { Charge } \\
\text { materials }\end{array}$ & Amount & C & Si & Mn & P & S & Fe \\
\hline Pig iron & $12 \%-15 \%$ & 4.13 & 1.91 & 0.14 & 0.075 & 0.025 & Bal. \\
Foundry return & $25 \%-30 \%$ & 3.68 & 2.21 & 0.18 & 0.01 & 0.026 & Bal. \\
Steel scrap & $55 \%-65 \%$ & 0.038 & 0.001 & 0.302 & 0.025 & 0.008 & Bal.
\end{tabular}

Table 3: Chemical compositions of Fe-Si-Mg alloy and post inoculant (wt.\%)

\begin{tabular}{ccccccccccc}
\hline Inoculant & Size & Si & $\mathbf{P}$ & $\mathbf{S}$ & $\mathbf{M g}$ & $\mathbf{C a}$ & $\mathbf{A l}$ & $\mathbf{B a}$ & $\mathrm{Fe}$ \\
\hline Fe-Si-Mg alloy & $20-25 \mathrm{~mm}$ & 47.5 & - & - & 5.82 & 1.23 & 0.92 & - & Bal. \\
Post inoculant & $4-8 \mathrm{~mm}$ & 74.62 & 0.035 & 0.004 & - & 1.13 & 1.41 & 2.47 & Bal.
\end{tabular}

Table 4: Chemical compositions of base and $0.4 \%, 0.6 \%$ and $0.8 \%$ inoculated metal (wt. $\%$ )

\begin{tabular}{|c|c|c|c|c|c|c|c|c|c|c|}
\hline Metal treatment & C & Si & Mn & $\mathbf{P}$ & $\mathbf{S}$ & $\mathrm{Cu}$ & Al & $\mathbf{C a}$ & $\mathbf{B a}$ & $\begin{array}{c}\text { Carbon } \\
\text { equivalent }\end{array}$ \\
\hline Base metal $(1,000 \mathrm{~kg})$ & 3.77 & 1.29 & 0.176 & 0.033 & 0.014 & 0.25 & 0.009 & 0.001 & 0.001 & 4.211 \\
\hline $\begin{array}{l}\text { Metal with } 0.4 \% \\
\text { inoculation }(4 \mathrm{~kg})\end{array}$ & 3.83 & 2.77 & 0.168 & 0.029 & 0.013 & 0.031 & 0.021 & 0.001 & 0.002 & 4.76 \\
\hline $\begin{array}{l}\text { Metal with } 0.6 \% \\
\text { inoculation }(6 \mathrm{~kg})\end{array}$ & 3.86 & 2.83 & 0.172 & 0.031 & 0.01 & 0.035 & 0.028 & 0.002 & 0.003 & 4.81 \\
\hline $\begin{array}{l}\text { Metal with } 0.8 \% \\
\text { inoculation }(8 \mathrm{~kg})\end{array}$ & 3.87 & 2.89 & 0.178 & 0.034 & 0.011 & 0.033 & 0.024 & 0.002 & 0.003 & 4.84 \\
\hline
\end{tabular}




\subsection{Microstructure observation and mechanical properties testing}

To observe the microstructure and test mechanical properties, the specimens of $50 \mathrm{~mm}$ (length) $\times 25 \mathrm{~mm}$ (width) were prepared with the thickness of $5 \mathrm{~mm}, 10 \mathrm{~mm}$ and $15 \mathrm{~mm}$, for $0.4 \%, 0.6 \%$, and $0.8 \%$ inoculated metal respectively. Before the microstructure analysis, specimens were well polished using emery papers of different grades followed by cloth polishing with diamond paste. Specimens were etched with $2 \%$ nital solution ( $2 \%$ concentrated nitric acid and $98 \mathrm{ml}$ methyl alcohol) after the polishing. Brinell hardness tests were carried out. A system integrated metallographic image analyzer was used to observe the microstructure of the specimens. Testing results are shown in Table 5. It can be seen that the nodularity is ranging from $87 \%$ to $97 \%$ and Brinell hardness $(\mathrm{BH})$ is ranging from 185 to 207 , showing that all the components produced in these experiments have good microstructure and mechanical properties.

Table 5: Nodularity and Brinell hardness (BH) of test specimens

\begin{tabular}{|c|c|c|c|c|c|c|c|c|c|}
\hline \multirow{2}{*}{$\begin{array}{c}\text { Sample } \\
\text { No. }\end{array}$} & \multicolumn{3}{|c|}{ Testing conditions } & \multicolumn{2}{|c|}{5 mm specimen } & \multicolumn{2}{|c|}{$10 \mathrm{~mm}$ specimen } & \multicolumn{2}{|c|}{$15 \mathrm{~mm}$ specimen } \\
\hline & Temp. $\left({ }^{\circ} \mathrm{C}\right)$ & $\begin{array}{c}\text { Inoculation } \\
(\%)\end{array}$ & $\begin{array}{l}\text { Carbon } \\
\text { equivalent (\%) }\end{array}$ & $\begin{array}{c}\text { Nodularity } \\
(\%)\end{array}$ & BH & $\begin{array}{c}\text { Nodularity } \\
(\%)\end{array}$ & BH & $\begin{array}{c}\text { Nodularity } \\
(\%)\end{array}$ & BH \\
\hline 1 & $1,400-1,350$ & 0.4 & 4.76 & 94 & 197 & 89 & 193 & 88 & 190 \\
\hline 2 & $1,350-1,300$ & 0.4 & 4.76 & 92 & 189 & 87 & 188 & 89 & 193 \\
\hline 3 & $1,300-1,250$ & 0.4 & 4.76 & 91 & 185 & 88 & 189 & 87 & 191 \\
\hline 4 & $1,400-1,350$ & 0.6 & 4.81 & 96 & 203 & 92 & 198 & 93 & 201 \\
\hline 5 & $1,350-1,300$ & 0.6 & 4.81 & 94 & 196 & 91 & 190 & 90 & 197 \\
\hline 6 & $1,300-1,250$ & 0.6 & 4.81 & 93 & 187 & 90 & 188 & 89 & 195 \\
\hline 7 & $1,400-1,350$ & 0.8 & 4.84 & 97 & 207 & 94 & 205 & 93 & 204 \\
\hline 8 & $1,350-1,300$ & 0.8 & 4.84 & 95 & 202 & 92 & 199 & 91 & 201 \\
\hline 9 & $1,300-1,250$ & 0.8 & 4.84 & 96 & 198 & 93 & 196 & 92 & 199 \\
\hline
\end{tabular}

\subsection{Experiment design for L-27 orthogonal array}

The experiments for L-27 orthogonal array were designed, and different sets of moulds were prepared. Four components can be produced in each mould box. The first set of mould boxes have the properties of moisture content $3 \%$, green compression strength $1,000 \mathrm{gm} \cdot \mathrm{cm}^{-2}$, permeability 160 and mould hardness 70 . The second set of mould boxes have the properties of moisture content $3.6 \%$, green compression strength 1,150 $\mathrm{gm} \cdot \mathrm{cm}^{-2}$, permeability 175 and mould hardness 80 . The third set of mould boxes have the properties of moisture content $4.2 \%$, green compression strength $1,300 \mathrm{gm} \cdot \mathrm{cm}^{-2}$, permeability 190 and mould hardness 90. A total of 45 mould boxes were prepared for each inoculated metal, and for each run in L-27 orthogonal array, 15 mould boxes were allotted.

Initially, the melt was poured at $1,400{ }^{\circ} \mathrm{C}$, and poured in 15 mould boxes for each set, 45 mould boxes were poured in total. Then the melt was poured at $1,350{ }^{\circ} \mathrm{C}$ and $1,300{ }^{\circ} \mathrm{C}$, also in 15 mould boxes for each set. The same procedure is repeated for metal with $0.4 \%, 0.6 \%$ and $0.8 \%$ inoculant. For each run, 60 components were produced and the defects were analyzed.

\subsection{Taguchi approach}

The Taguchi design of experimentation is one of the techniques which are used widely. The Taguchi method involves reducing the variation in a process through a robust design of experiments. The overall objective of the method is to produce a high quality product at low cost.

Taguchi's approach was used for optimizing process parameters of ductile iron casting. The Design of Experiments (DOE) was carried out as follows:

- Choosing appropriate responses (output variables).

- Choosing appropriate factors (input variables).

- Setting appropriate factor ranges or levels.

- Creating documentation for the experiment.

- Managing the experiment as it takes place.

- Reporting and presenting results (ANOVA).

DOE was selected based on the seven casting parameters with three levels each. L-27 orthogonal array was applied, which is composed of 3 columns and 27 rows, which means that 27 experiments were carried out.

The process parameters and their workable ranges for the experiment were chosen from the data available in research studies $[2,6,7]$. The selected process parameters and their levels are given in Table 2. The selected casting parameters for this study are: pouring temperature, inoculation, carbon equivalent, moisture content, green compression strength, permeability and mould hardness.

Table 6 shows the casting process input variables and experiment design levels. The Taguchi method was applied to the experimental data using statistical software "MINITAB 17". 
Table 6: Selected process parameters and their levels

\begin{tabular}{lccc}
\multicolumn{1}{c}{ Process parameters } & Level 1 & Level 2 & Level 3 \\
\hline Pouring temperature $\left({ }^{\circ} \mathrm{C}\right)$ & 1,300 & 1,350 & 1,400 \\
Inoculation (wt.\%) & 0.4 & 0.6 & 0.8 \\
Carbon equivalent (\%) & 4.76 & 4.81 & 4.84 \\
Moisture content $(\%)$ & 3 & 3.6 & 4.2 \\
$\begin{array}{l}\text { Green compression } \\
\text { strength }\left(\mathrm{gm} \cdot \mathrm{cm}^{-2}\right)\end{array}$ & 1,000 & 1,150 & 1,300 \\
$\begin{array}{l}\text { Permeability } \\
\text { Mould hardness }\end{array}$ & 160 & 175 & 190 \\
\hline
\end{tabular}

\section{$1.5 \mathrm{~S} / \mathrm{N}$ ratio calculation}

The $\mathrm{S} / \mathrm{N}$ ratios were obtained using Taguchi's methodology. The 'signal' is the desirable value (mean) and the 'noise' is the undesirable value (standard deviation). Thus the $\mathrm{S} / \mathrm{N}$ ratio represents the amount of variation present in the performance characteristic. Depending upon the objective of the performance characteristic, there can be various types of $\mathrm{S} / \mathrm{N}$ ratios.

In this study, "S/N Ratio $=-10 \times \log 10\left(\operatorname{sum}\left(1 / Y^{2}\right) / n\right) "{ }^{[26]}$ is taken for optimization of the process parameters. Where ' $Y$ ' is the Response and ' $n$ ' is the number of trials of each run. In this experimentation, $n=1$ for each run.

Table 7 shows the orthogonal array for different signals (pouring temperature, inoculation, carbon equivalent, moisture content, green compression strength, permeability, mould hardness), noise or response (approved percent) and $\mathrm{S} / \mathrm{N}$ ratio for each run.

Table 7: L-27 Orthogonal array $-\mathrm{S} / \mathrm{N}$ ratio

\begin{tabular}{|c|c|c|c|c|c|c|c|c|}
\hline $\begin{array}{c}\text { Pouring } \\
\text { temperature }\end{array}$ & $\begin{array}{c}\text { Inoculation } \\
(\%)\end{array}$ & $\begin{array}{l}\text { Carbon } \\
\text { equivalent }\end{array}$ & $\begin{array}{c}\text { Moisture } \\
\text { content (\%) }\end{array}$ & GCS & Permeability & $\begin{array}{l}\text { Mould } \\
\text { Hardness }\end{array}$ & $\begin{array}{c}\text { Approved } \\
(\%)\end{array}$ & S/N ratio \\
\hline 1,400 & 0.4 & 4.76 & 3 & 1,000 & 160 & 70 & 91.67 & 39.24 \\
\hline 1,350 & 0.4 & 4.76 & 3 & 1,000 & 160 & 70 & 88.33 & 38.92 \\
\hline 1,300 & 0.4 & 4.76 & 3 & 1,000 & 160 & 70 & 90.00 & 39.08 \\
\hline 1,400 & 0.6 & 4.81 & 3 & 1,000 & 160 & 70 & 95.00 & 39.55 \\
\hline 1,350 & 0.6 & 4.81 & 3 & 1,000 & 160 & 70 & 93.33 & 39.40 \\
\hline 1,300 & 0.6 & 4.81 & 3 & 1,000 & 160 & 70 & 88.33 & 38.92 \\
\hline 1,400 & 0.8 & 4.84 & 3 & 1,000 & 160 & 70 & 93.33 & 39.40 \\
\hline 1,350 & 0.8 & 4.84 & 3 & 1,000 & 160 & 70 & 91.67 & 39.24 \\
\hline 1,300 & 0.8 & 4.84 & 3 & 1,000 & 160 & 70 & 86.67 & 38.76 \\
\hline 1,400 & 0.4 & 4.76 & 3.6 & 1,150 & 175 & 80 & 91.67 & 39.24 \\
\hline 1,350 & 0.4 & 4.76 & 3.6 & 1,150 & 175 & 80 & 90.00 & 39.08 \\
\hline 1,300 & 0.4 & 4.76 & 3.6 & 1,150 & 175 & 80 & 86.67 & 38.76 \\
\hline 1,400 & 0.6 & 4.81 & 3.6 & 1,150 & 175 & 80 & 93.33 & 39.40 \\
\hline 1,350 & 0.6 & 4.81 & 3.6 & 1,150 & 175 & 80 & 90.00 & 39.08 \\
\hline 1,300 & 0.6 & 4.81 & 3.6 & 1,150 & 175 & 80 & 88.33 & 38.92 \\
\hline 1,400 & 0.8 & 4.84 & 3.6 & 1,150 & 175 & 80 & 96.67 & 39.71 \\
\hline 1,350 & 0.8 & 4.84 & 3.6 & 1,150 & 175 & 80 & 95.00 & 39.55 \\
\hline 1,300 & 0.8 & 4.84 & 3.6 & 1,150 & 175 & 80 & 93.33 & 39.40 \\
\hline 1,400 & 0.4 & 4.76 & 4.2 & 1,300 & 190 & 90 & 83.33 & 38.42 \\
\hline 1,350 & 0.4 & 4.76 & 4.2 & 1,300 & 190 & 90 & 86.67 & 38.76 \\
\hline 1,300 & 0.4 & 4.76 & 4.2 & 1,300 & 190 & 90 & 85.00 & 38.59 \\
\hline 1,400 & 0.6 & 4.81 & 4.2 & 1,300 & 190 & 90 & 91.67 & 39.24 \\
\hline 1,350 & 0.6 & 4.81 & 4.2 & 1,300 & 190 & 90 & 90.00 & 39.08 \\
\hline 1,300 & 0.6 & 4.81 & 4.2 & 1,300 & 190 & 90 & 93.33 & 39.40 \\
\hline 1,400 & 0.8 & 4.84 & 4.2 & 1,300 & 190 & 90 & 98.33 & 39.85 \\
\hline 1,350 & 0.8 & 4.84 & 4.2 & 1,300 & 190 & 90 & 96.67 & 39.71 \\
\hline 1,300 & 0.8 & 4.84 & 4.2 & 1,300 & 190 & 90 & 96.67 & 39.71 \\
\hline
\end{tabular}




\section{Sample calculation}

Run: 1

$Y=91.67, n=1$

$\mathrm{S} / \mathrm{N}$ ratio $=-10 \times \log 10\left(\operatorname{sum}\left(1 / 91.67^{2}\right) / 1\right)=39.24$

Figure 1 shows the main effects plot for different $\mathrm{S} / \mathrm{N}$ ratios. Larger is better.

Table 8 shows the response table for $\mathrm{S} / \mathrm{N}$ ratios. Optimum values of different parameters were chosen according to Table 8 .

\section{Results and discussion}

According to Fig. 1 and Table 8, the optimum levels of different casting process parameters were obtained as shown in Table 9.

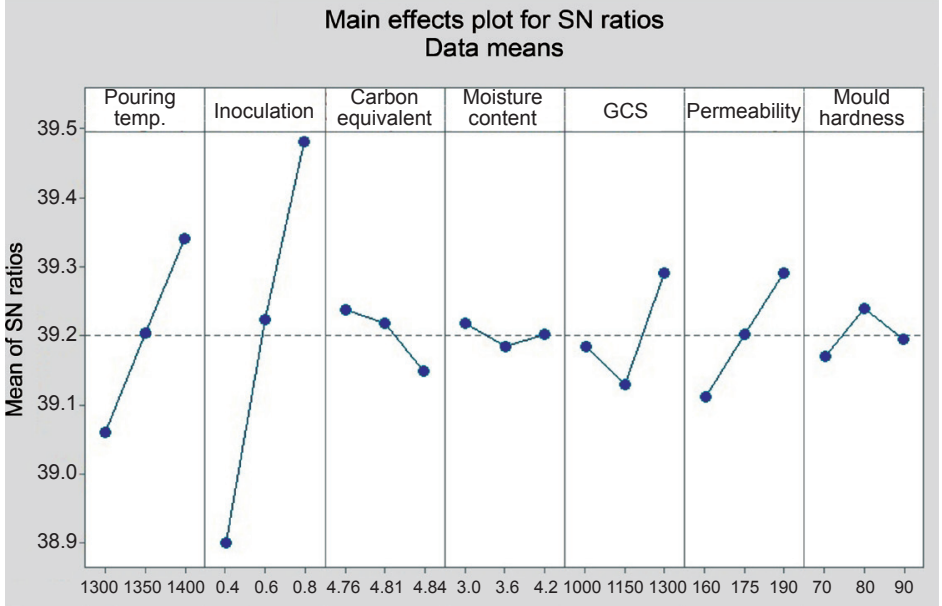

Fig. 1: Main effects plot for S/N ratios (GCS - green compression strength)

Table 8: Response table for $\mathrm{S} / \mathrm{N}$ ratios

\begin{tabular}{ccccccccc} 
Level & $\begin{array}{c}\text { Pouring } \\
\text { temperature }\end{array}$ & Inoculation & $\begin{array}{c}\text { Carbon } \\
\text { equivalent }\end{array}$ & $\begin{array}{c}\text { Moisture } \\
\text { content }\end{array}$ & GCS & $\begin{array}{c}\text { Permeability } \\
\text { Mould } \\
\text { hardness }\end{array}$ \\
\hline 1 & 39.17 & 38.9 & 39.29 & 39.32 & 39.34 & 39.2 & 39.29 \\
2 & 39.24 & 39.22 & 39.39 & 39.14 & 39.2 & 39.29 & 39.13 \\
3 & 39.2 & 39.48 & 38.95 & 39.14 & 39.06 & 39.11 & 39.18 \\
Delta & 0.07 & 0.58 & 0.41 & 0.19 & 0.28 & 0.18 & 0.16 \\
Rank & 7 & 1 & 2 & 4 & 3 & 5 & 6
\end{tabular}

Table 9: Optimum levels of process parameters

\begin{tabular}{|cc|}
\hline Process parameters & Optimum level \\
\hline Pouring temperature $\left({ }^{\circ} \mathrm{C}\right)$ & 1,350 \\
Inoculation $(\%)$ & 0.8 \\
Carbon equivalent $(\%)$ & 4.81 \\
Moisture content $(\%)$ & 3 \\
Green compression & 1,000 \\
Strength $\left(\mathrm{gm} \cdot \mathrm{cm}^{-2}\right)$ & 175 \\
Permeability & 70 \\
Mould hardness &
\end{tabular}

Table 10 shows the rejection of components due to casting defects at optimum condition. It is clearly shown that the rejection percentage is considerably reduced from $16.98 \%$ (Table 1 ) to $6.07 \%$.

Figure 2 shows the comparison of various defects before and after the optimization. It clearly shows that all defects were considerably reduced after the optimization.

\subsection{Analysis of variance (ANOVA)}

ANOVA is used to estimate the percentage contribution of various process parameters to the selected performance characteristics. This gives the information about how significant is the effect of each controlled parameter on the quality characteristics of interest. The total variation in the result is the sum of variation due to various controlled factors,
Table 10: Rejection of components due to casting defects after optimization

\begin{tabular}{ccc} 
Defect & Rejected no. & Rejection (\%) \\
\hline Crack & 22 & 1.47 \\
Cold shut & 16 & 1.07 \\
Poor mould & 13 & 0.87 \\
Mismatch & 10 & 0.67 \\
Fettling fault & 8 & 0.53 \\
Slag & 7 & 0.47 \\
Run out & 6 & 0.40 \\
Scab & 2 & 0.13 \\
Swell & 3 & 0.20 \\
Less hardness & 2 & 0.13 \\
Others & 2 & 0.13 \\
Inspected & 91 & 6.07 \\
components $=1,620$ & &
\end{tabular}

their interactions and due to experimental error. ANOVA for raw data and $\mathrm{S} / \mathrm{N}$ data has been performed to identify the significant parameters and quantifies their effect on the performance characteristics. The ANOVA based on the raw data identifies the factors which affect the average response rather than reducing variation. However, ANOVA based on the $\mathrm{S} / \mathrm{N}$ ratio takes both these aspects into account.

Table 11 shows the ANOVA analysis for different process parameters based on the $\mathrm{S} / \mathrm{N}$ ratio. The table was generated 

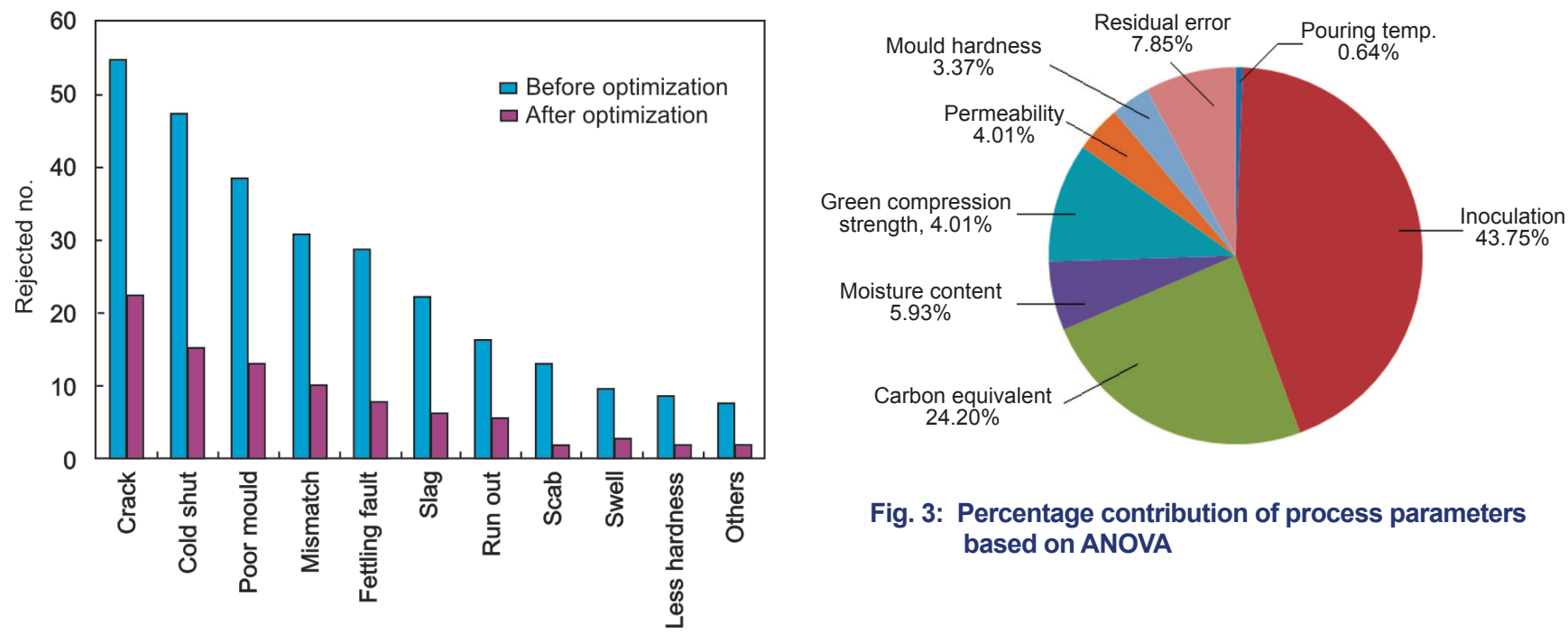

Fig. 2: Rejected no. of casting before and after optimization

Table 11: Analysis of variance for means

\begin{tabular}{|c|c|c|c|c|c|c|c|}
\hline $\begin{array}{l}\text { Process } \\
\text { parameters }\end{array}$ & $\begin{array}{l}\text { Degrees of } \\
\text { freedom }\end{array}$ & $\begin{array}{l}\text { Sequential } \\
\text { sum of } \\
\text { squares }\end{array}$ & $\begin{array}{l}\text { Adjusted sum } \\
\text { of squares }\end{array}$ & $\begin{array}{l}\text { Adjusted mean } \\
\text { squares }\end{array}$ & F-ratio & P-value & $\begin{array}{c}\text { Percentage of } \\
\text { contribution }\end{array}$ \\
\hline $\begin{array}{c}\text { Pouring } \\
\text { temperature }\end{array}$ & 2 & 2.469 & 2.469 & 1.235 & 0.49 & 0.624 & 0.64 \\
\hline Inoculation & 2 & 168.5 & 168.5 & 84.259 & 33.43 & 0.000 & 43.75 \\
\hline $\begin{array}{l}\text { Carbon } \\
\text { equivalent }\end{array}$ & 2 & 93.21 & 93.21 & 46.605 & 18.49 & 0.000 & 24.20 \\
\hline Moisture content & 2 & 22.84 & 22.84 & 11.42 & 4.53 & 0.034 & 5.93 \\
\hline $\begin{array}{l}\text { Green } \\
\text { compression } \\
\text { strength }\end{array}$ & 2 & 39.506 & 39.506 & 19.753 & 7.84 & 0.007 & 10.26 \\
\hline Permeability & 2 & 15.432 & 15.432 & 7.716 & 3.06 & 0.084 & 4.01 \\
\hline Mould hardness & 2 & 12.963 & 12.963 & 6.481 & 2.57 & 0.118 & 3.37 \\
\hline Residual error & 12 & 30.247 & 30.247 & 2.521 & & & 7.85 \\
\hline Total & 26 & 385.185 & & & & & 100 \\
\hline
\end{tabular}

using the statistical software Minitab 17. Table 11 shows that inoculation is the most significant factor having the F-Ratio of 33.43 and contributing $43.75 \%$; pouring temperature is the least significant factor having the F-Ratio of 0.49 and contributing $0.64 \%$.

Figure 3 shows the contribution percentage of different process parameters based on ANOVA. It shows that inoculation contributes the largest percentage.

\subsection{Study of inoculation with other parameters using response surface methodology}

Analysis using the Taguchi method mentioned above is an analysis only for the main factors that affect castings' acceptance percentage without any consideration of correlation between factors. Therefore, a study was performed using Response Surface Methodology to analyze the correlation between factors. In the Taguchi analysis, it is found that inoculation is the most significant factor. Hence, the contour plots and surface plots were generated based on acceptance percentage, inoculation and other factors using Minitab17 software. Inoculation levels were taken at X-axis and other factors taken at Y-axis. Different responses based on the approved percentage were shown using contour plot and surface plot. Figures 4 through 9 show that an increase in inoculation and parameters such as pouring temperature, carbon equivalent, moisture content, green compression strength, permeability and mould hardness results in an increase of acceptance percentage of casting components.

\section{Conclusions}

The conclusions drawn from the work carried out are as follows:

(1) Optimum process parameters were found based on the 27 runs using the Taguchi methodology: pouring temperature $1,350{ }^{\circ} \mathrm{C}$, inoculation $0.8 \%$, carbon equivalent $4.81 \%$, moisture 

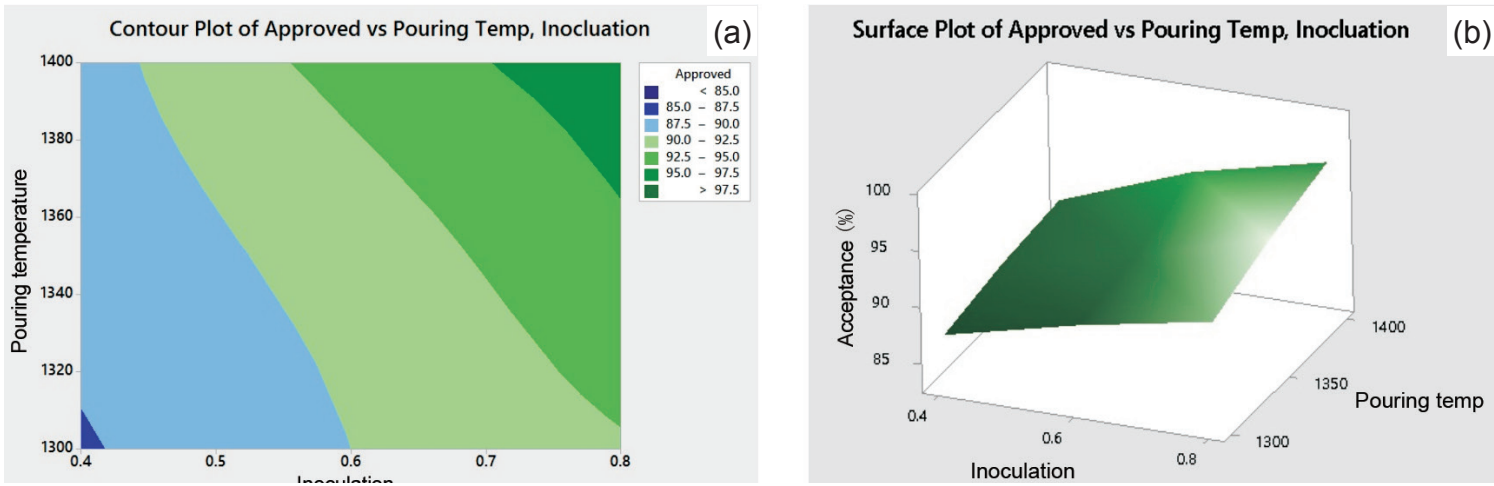

Fig. 4: Contour plot (a) and surface plot (b) of casting acceptance percentage vs pouring temperature and inoculation
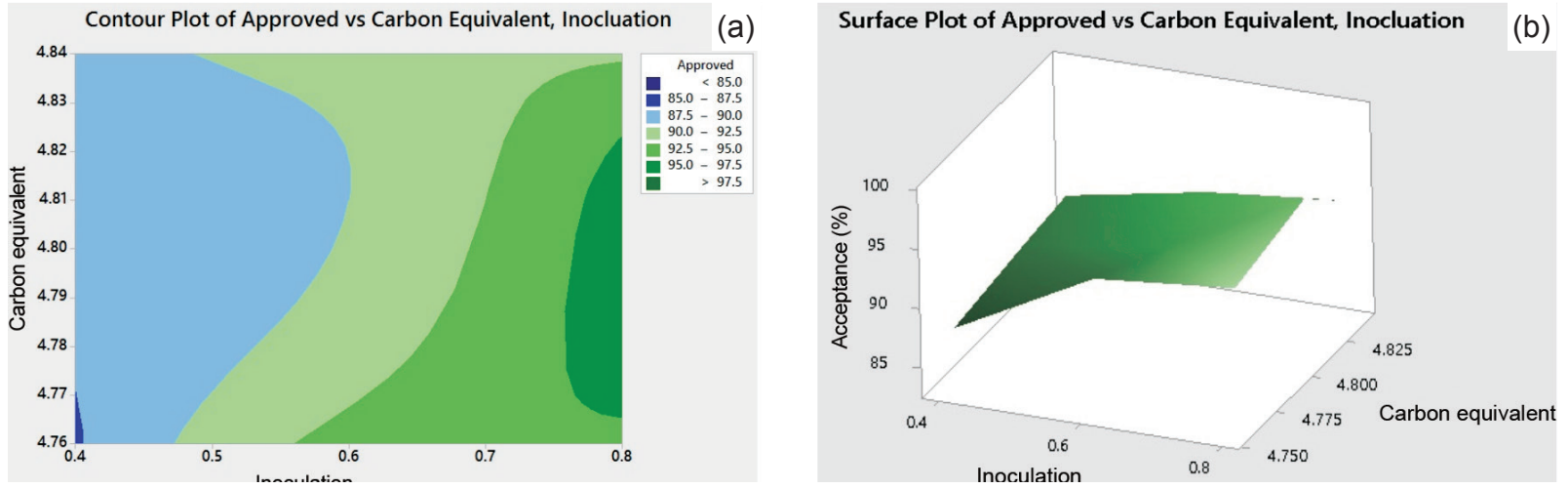

Fig. 5: Contour plot (a) and surface plot (b) of casting acceptance percentage vs carbon equivalent (a) and inoculation (b)
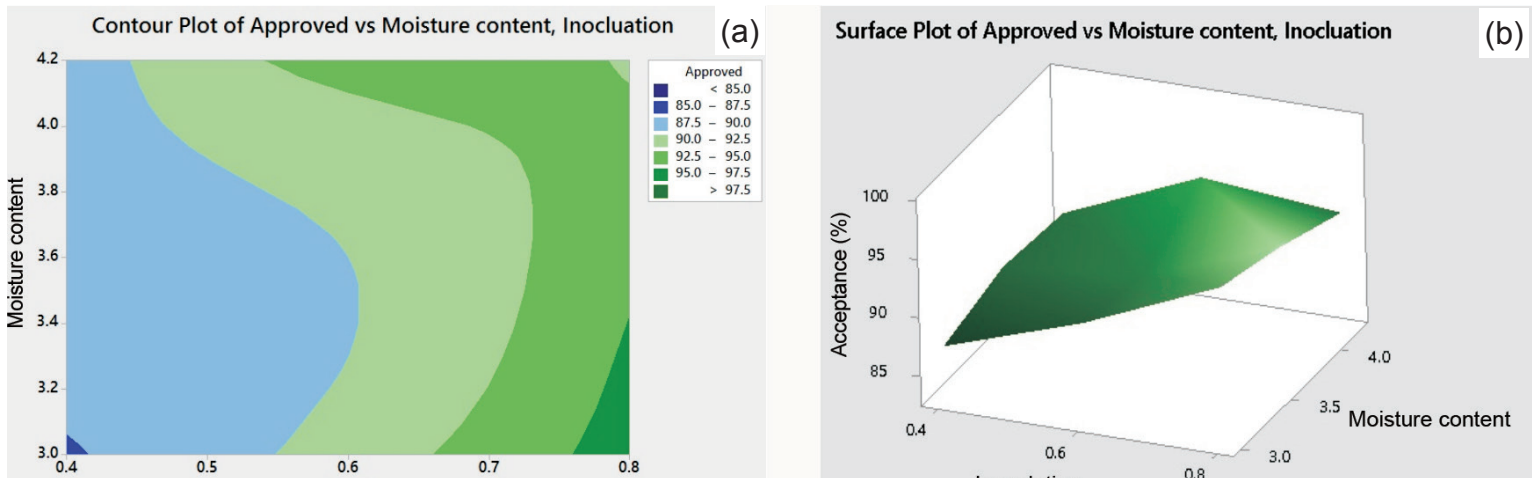

Fig. 6: Contour plot (a) and surface plot (b) of casting acceptance percentage vs moisture content and inoculation
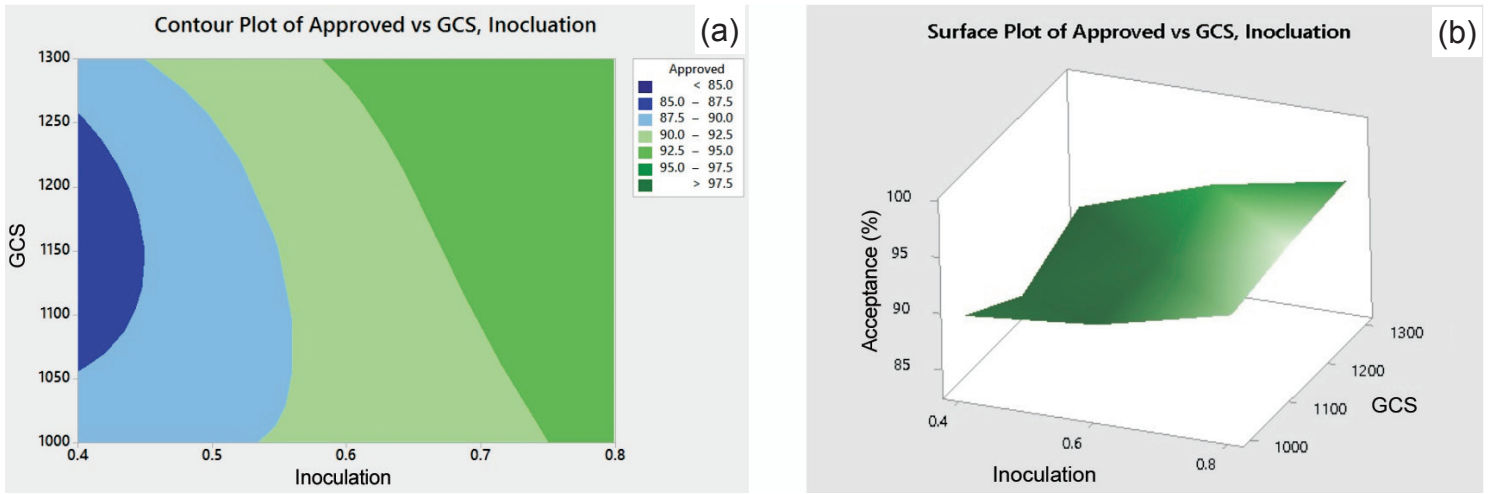

Fig. 7: Contour plot (a) and surface plot (b) of casting acceptance percentage vs GCS and inoculation 


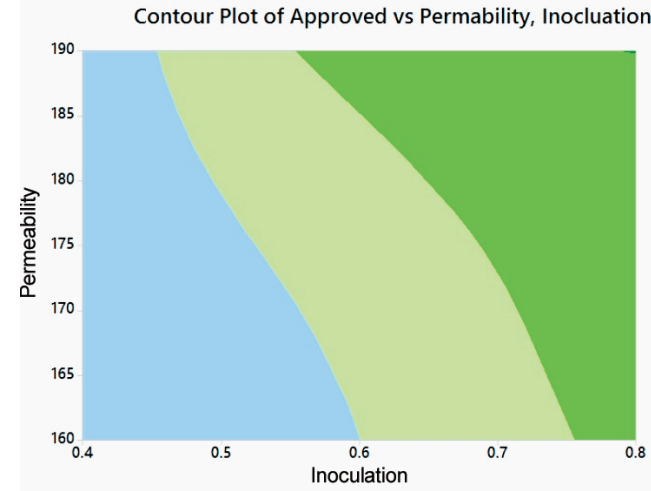

(a)

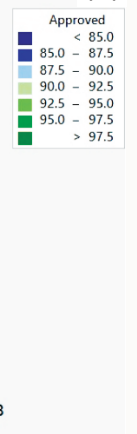

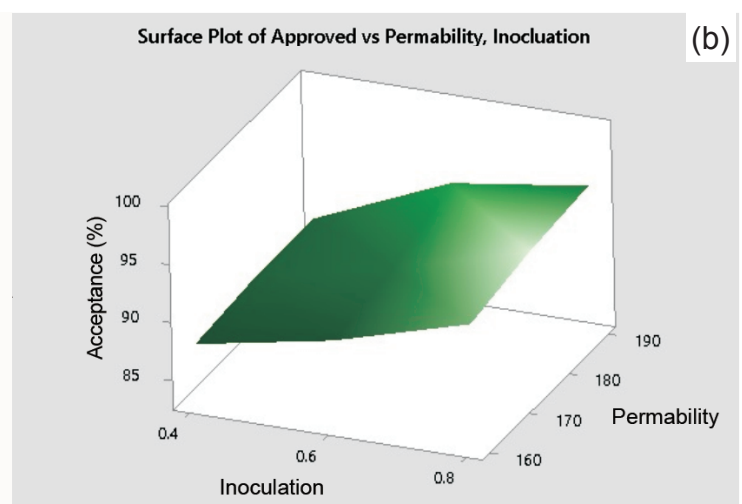

Fig. 8: Contour plot (a) and surface plot (b) of casting acceptance percentage vs permeability and inoculation
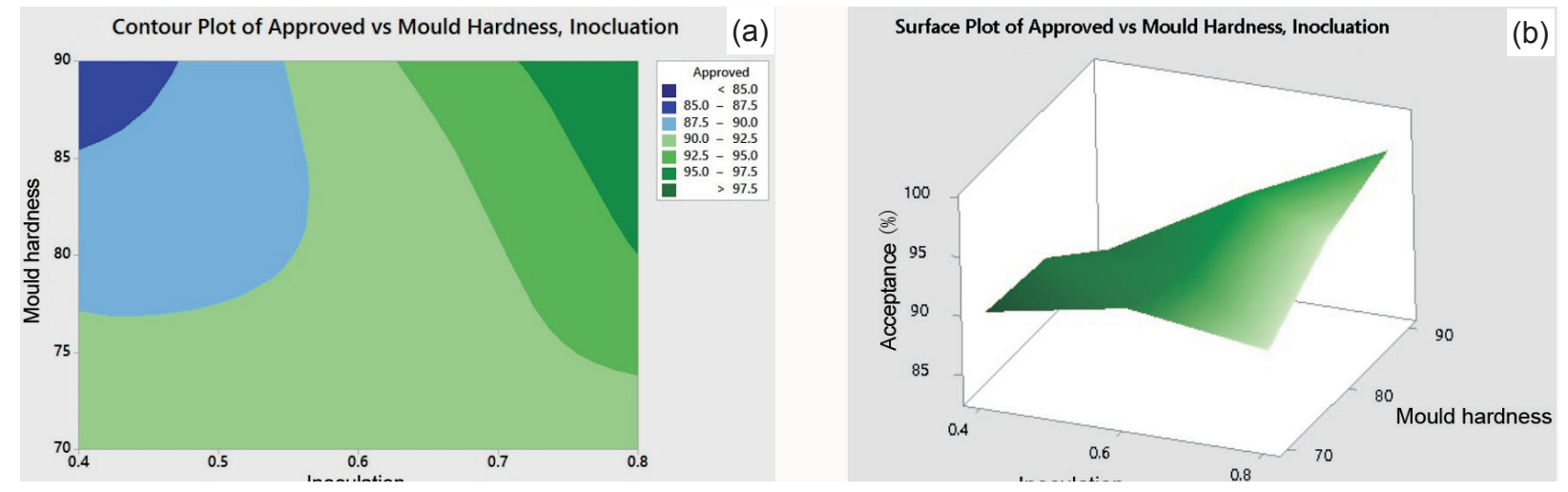

Fig. 9: Contour plot (a) and surface plot (b) of casting acceptance percentage vs mould hardness and inoculation

content $3 \%$, green compression strength $1,300 \mathrm{gm} \cdot \mathrm{cm}^{-2}$, permeability 175 , and mould Brinell hardness 90 . After the optimization, it was found that the rejection rate was reduced from $16.98 \%$ to $6.07 \%$.

(2) The analysis of variance for the acceptance percentage concludes that inoculation is the most significant parameter affecting the castings' quality with a contribution percentage of $44 \%$.

(3) Contour and surface plots show that an increase in inoculation results in a significant improvement in acceptance percentage of ductile iron castings.

\section{References}

[1] Senthilkumar B, Ponnambalam S G, Jawahar N, et al. Process factor optimization for controlling pull-down defects in iron castings. Journal of Materials Processing Technology, 2009, 209: 554-560.

[2] Madtha L S and Narendra B B R. Experimental Behavioural Study of Ductile Cast Iron Microstructure and Its Mechanical Properties. International Journal of Engineering Research and Applications, 2013, 3(3): 1470-1475.

[3] Bahubali B S and Vasudev D S. The Effect of Inoculation on Microstructure and Mechanical Properties of Ductile Iron. IOSR Journal of Mechanical and Civil Engineering, 2013, 5(6): 17-23.

[4] Jezierski J and Bartocha D. Properties of cast iron modifying with use of new inoculants. Journal of Achievements in Materials and Manufacturing Engineering, 2007, 22(1): 25-28.

[5] Aghakhani M, Mehrdad E, Hayati E, et al. Parametric Optimization of Gas Metal Arc Welding Process by Taguchi
Method on Weld Dilution. International Journal of Modeling and Optimization, 2011, 1(3): 216-220.

[6] Sylvester $O$ and Raymond T. Study of carbon and silicon loss through oxidation in cast iron base metal using rotary furnace for melting. Leonardo Electronic Journal of Practices and Technologies, 2015, 26: 59-64.

[7] Ganesh G P and Inamdar K H. Optimization of Casting Process Parameters using Taguchi Method. International Journal of Engineering Development and Research, 2014, 2(2): 2506-2511.

[8] Mekonnen L N and Ajit P S. Optimization of aluminium blank sand casting process by using Taguchi's robust design method. International Journal for Quality Research, 2012, 6(1): 81-97.

[9] Rasik A U and Ishwar P K. Optimization of Sand Casting Process Parameter Using Taguchi Method in Foundry. International Journal of Engineering Research \& Technology, 2012, 1(7): 1-9.

[10] Pradeep A and Muthukumaran S. An analysis to optimize the process parameters of friction stir welded low alloy steel plates. International Journal of Engineering, Science and Technology, 2013, 5(3): 25-35.

[11] Uday A D and Rahul C B. Casting Defect Analysis using Design of Experiments (DoE) and Computer Aided Casting Simulation Technique. Procedia CIRP, 2013, 7: 616-621.

[12] Prajapati D R and Cheema D S. Optimization of Weld Crack Expansion Defect of Wheel Rims by Using Taguchi Approach: A Case Study. International Journal of Innovative Research in Science, Engineering and Technology, 2013, 2(8): 3437-3446.

[13] Venkata R M, Krishna M R G, Hanumantha R D, et al. Optimization and Effect of Process Parameters on Tool Wear in Turning of Titanium Alloy under Different Machining Conditions. International Journal of Materials, Mechanics and Manufacturing, 2014, 2(4): 272-277. 
[14] Vipindas M P and Govindan P. Taguchi-Based Optimization of Surface Roughness in CNC Turning Operation. International Journal of Latest Trends in Engineering and Technology, 2013, 2(4): 454-463.

[15] Mahendra G R and Nilesh A J. An optimization of forging process parameters by using Taguchi Method: An industrial case study. International Journal of Scientific and Research Publications, 2014, 4(6): 1-7.

[16] Sarkar T and Sutradhar G. Study of Factors Influencing Hardness Behaviour of Austempered Gray Iron (AGI) Using Taguchi Method. International Journal of Recent Development in Engineering and Technology, 2014, 3(5): 10-16.

[17] Krishankant, Jatin T, Mohit B, et al. Application of Taguchi Method for Optimizing Turning Process by the effects of Machining Parameters. International Journal of Engineering and Advanced Technology, 2012, 2(1): 263-274.

[18] Amit A, Deepak Ue, Bhargav P, et al. Statistical and Regression Analysis of Vibration of Carbon Steel Cutting Tool for Turning of En24 Steel Using Design of Experiments. International Journal of Recent advances in Mechanical Engineering, 2014, 3(3): 137-151.

[19] Mahesh N A and Shrikant V K. Optimization of die-casting process parameters using DOE. International Journal of Engineering Research and General Science, 2015, 3(2): 1314-1325.

[20] Chauhan V and Jadoun R S. Parametric Optimization of Mig Welding For Stainless Steel (Ss-304) and Low Carbon Steel
Using Taguchi Design Method. International Journal of Recent Scientific Research, 2015, 6(2): 2662-2666.

[21] Rama R S and Padmanabhan G. Application of Taguchi methods and ANOVA in optimization of process parameters for metal removal rate in electrochemical machining of $\mathrm{Al} / 5 \% \mathrm{SiC}$ composites. International Journal of Engineering Research and Applications, 2012, 2(3): 192-197.

[22] Song Liu. Foundry and Development of Ductile Iron Crankshaft. The Open Mechanical Engineering Journal, 2015, 9: 791-796.

[23] Thacker K, Joshi H, Patel N J, et al. Analysis and Optimization of parameters for casting ductile iron pipes. International Journal of Engineering Research and General Science, 2015, 3(3): 403-429.

[24] Kompan C and Somkiat J. Optimization Parameters of Tool Life Model Using the Taguchi Approach and Response Surface Methodology. International Journal of Computer Science Issues, 2012, 9(1): 120-125.

[25] Raykundaliya D P and Shanubhogue A. Comparison Study: Taguchi Methodology vis.-a-vis. Response Surface Methodology through a Case Study of Accelerated Failure in Spin-on-Filter. International Advanced Research Journal in Science, Engineering and Technology, 2015, 2(3): 1-5.

[26] Phillip.J.Ross. Taguchi Techniques for Quality Engineering, First Edition, McGraw Hill, New York, 1988: 173. 